\title{
Plasma amino acid concentrations in healthy and cognitively impaired oldest-old individuals: associations with anthropometric parameters of body composition and functional disability
}

\author{
Giovanni Ravaglia ${ }^{1}$, Paola Forti ${ }^{1}$, Fabiola Maioli ${ }^{1}$, Giampaolo Bianchi ${ }^{1}$, Loredana Sacchetti ${ }^{1}$, \\ Teresa Talerico ${ }^{1}$, Valeria Nativio ${ }^{1}$, Erminia Mariani ${ }^{2}$ and Pierluigi Macini ${ }^{3}$ \\ ${ }^{1}$ Department of Internal Medicine, Cardioangiology, and Hepatology; \\ University Hospital S. Orsola-Malpighi, Bologna, Italy \\ ${ }^{2}$ Laboratory of Immunology and Genetics, Codivilla Putti Research Institute, \\ Rizzoli Orthopaedic Institute, 40136 Bologna, Italy \\ ${ }^{3}$ Public Prevention Service, Health Council Department Emilia Romagna Region, Bologna, Italy
}

(Received 29 November 2001 - Revised 22 May 2002 - Accepted 2 July 2002)

\begin{abstract}
Only a few reports exist of plasma amino acid profiles in the oldest-old, and none exist of the oldest-old with cognitive problems. Therefore, we measured fasting plasma amino acid concentrations in twenty-three healthy community-dwellers aged 90-103 years (group A); eighteen community-dwellers with mild cognitive impairment without dementia aged 91-104 years (group B); thirty-three patients with dementia aged 96-100 years (group C); and sixty healthy young controls aged 20-50 years. Biochemical and anthropometric parameters, and the basic activities of daily living (ADL) were also measured. Independent of cognitive status, in all oldest-old groups, essential:non essential amino acids (EAA:NEAA) was lower than in young controls and positively associated with body muscle mass. Patients with dementia were further characterized by a negative association between EAA:NEAA and the number of dependent ADL. All oldest-old groups had higher values of tyrosine:other large neutral amino acids (LNAA) than young controls. Groups B and C also had a higher phenylalanine: other LNAA. These data show that abnormalities in plasma amino acid profile are common in oldest-old individuals independent of their cognitive status, but that, in oldest-old patients with dementia, they are associated with functional disability. The abnormalities in phenylalanine and tyrosine plasma availability could contribute to the cause or aggravation of concurrent cognitive problems because these amino acids are neurotransmitter precursors and compete with other LNAA for transport into the brain.
\end{abstract}

Plasma amino acids: Body composition: Cognitive function: Physical disability: Oldest-old

Fasting plasma amino acids reflect recent protein intake and can be altered by a deficient intake of any essential amino acid (EAA), by an imbalance of the amino acids in the dietary proteins, or by a deficient protein-energy intake (Young, 1990). Plasma amino acids may also be affected by liver (Zoli et al. 1981) and kidney failure (Laidlaw et al. 1994; Fiorini \& Cavatorta, 1997), alterations of glucose tolerance (Felig \& Bergman, 1995), and hypermetabolic conditions associated with infections and other inflammatory disorders (Young, 1990).
According to experimental results, some amino acids (phenylalanine (Phe), tyrosine (Tyr), tryptophan, histidine, arginine (Arg), threonine, glycine (Gly)) act as neurotransmitter precursors, and their plasma concentrations might be a regulating factor in brain function (Lieberman, 1999).

The prevalence of nutritional (Schlienger et al. 1995) and cognitive disorders (Ritchie \& Kildea, 1995) increases with age, but only a few studies have investigated the plasma amino acid pattern of elderly people (Rudman et al. 1989; Jeevanandam et al. 1990). Even fewer reports

Abbreviations: ADL, activities of daily living; Arg, arginine; BCAA, branched-chain amino acids; Cit, citrulline; DSM-IV, Diagnostic and Statistical Manual of Mental Disorders, 4th ed.; EAA, essential amino acid; Gly, glycine; IGF-1, insulin-like growth factor 1; LNAA, large neutral amino acids; NEAA, non-essential amino acids; Phe, phenylalanine; Tyr, tyrosine.

* Corresponding author: Professor Giovanni Ravaglia, fax + 39051 340877, email ravaglia@almadns.unibo.it 
(Bancel et al. 1994; Polge et al. 1997) exist of the amino acid profile in the age group known as the oldest-old ( $\geq 85$ years of age), and no data are available about plasma amino acids of oldest-old individuals with cognitive problems.

An inadequate dietary intake leads not only to changes in fasting amino acid profile, but also to changes in body muscle and fat mass and in tissue biochemistry that may affect health status and functional performance of elderly people (Raynaud-Simon \& Lesourd, 2000). Several techniques exist for the assessment of these changes in human subjects, but most of them are too invasive and complex for routine use in the elderly. Along with clinical data, simple and reliable, although somewhat gross, diagnostic parameters of protein-energy malnutrition generally used in geriatric practice are anthropometric measurements, which give information on the status of muscle and fat mass (World Health Organization, 1998), and biochemical tests aimed to evaluate body visceral transport proteins such as serum albumin (Constans et al. 2000).

In the present study we aimed to compare the fasting amino acid profile of healthy and cognitively impaired over-90-year-olds with the fasting amino acid profile of healthy young controls. We also investigated the relationships among plasma amino acid profile, anthropometric and biochemical markers of protein-energy malnutrition routinely used in geriatric practice, and physical disability.

\section{Subjects and methods}

\section{Subjects}

In order to create a bank of biomedical data and biological material available for studies of ageing, from January 1994 to January 1996 we recruited by several methods (advertisement, lists of medical practitioners, demographic lists from municipality registry offices) 160 over-90-yearolds resident in the provinces of Bologna and Ravenna (Emilia Romagna Region, Northern Italy) who were not hospitalized and were willing to undergo a standardized comprehensive geriatric assessment and venous blood draw. The procedure was performed with informed consent of the subjects or their next-of-kin, and with approval of the institutional review board of the Department of Internal Medicine, Cardioangiology, and Hepatology. Selected subgroups of these subjects have been described previously elsewhere (Ravaglia et al. 1996, 1997a,b, 1999). Due to the mixed recruitment procedure used, our database cannot be considered representative of the general Northern Italian oldest-old population.

Briefly, our assessment included for each subject: (1) a standardized interview for the collection of socio-demographic and medical data; (2) a thorough medical and and neurological examination; (3) a performance-based assessment of the independence in the six basic activities of daily living (ADL) (Katz et al. 1970); (4) cognitive testing by the Italian version of the thirty-item Mini Mental State Examination (Valente et al. 1992); (5) drawing of an overnight fast venous blood sample for blood routine chemistry and, when available, surplus serum and plasma storage; (6) recumbent anthropometric measurements according to standardized procedures (Ravaglia et al. 1997b). BMI was calculated as weight $(\mathrm{kg})$ divided by the square of the height $(\mathrm{m})$ calculated from the kneeheight measurement (Chumlea et al. 1985). Arm muscle area and arm fat area were calculated from mid-arm circumference and triceps skinfold thickness using standard formulas (Frisancho, 1981).

For the purposes of the present study, we selected seventy-four subjects (twenty-seven men and forty-seven women) who were assigned to group A, B or C.

Group A ( $n$ 23, age range 90-103 years) included community-dwelling healthy subjects who had Mini Mental State Examination scores in the normal range (20-30) according to Cummings' (1993) education-specific cut-off points (19/30 for 0 to 4 years of education, 23/30 for 5 to 8 years, $27 / 30$ for 9 to 12 years, $29 / 30$ for 13 or more years), functioned well in their surroundings, and fulfilled the health admission criteria of the SENIEUR protocol for gerontological studies in man (Ligthart et al. 1984). Briefly, SENIEUR exclusion criteria are: (1) clinical evidence of infective, inflammatory, neoplastic, and other acute or chronic disease including protein-energy malnutrition (as defined by clinical judgment and BMI $<20 \mathrm{~kg} / \mathrm{m}^{2}$ for females and $<22 \mathrm{~kg} / \mathrm{m}^{2}$ for males); (2) alteration of one or more of several laboratory indices, including erythrocyte sedimentation rate, haemoglobin, mean corpuscular volume, leucocyte count, urea, glucose, cholesterol and triacylglycerols, alkaline phosphatase, aspartate aminotransferase, alanine aminostransferase, serum protein electrophoresis, and urinalysis; (3) prescribed medication for treatment of acute or chronic disorders.

Group B ( $n$ 18, age range 91-104 years) included community-dwellers with Mini Mental State Examination scores below the education-adjusted cut-off points (range 19-22), but whose cognitive problems were not severe enough to meet the criteria for dementia stated by the American Psychiatric Association (1994) in the 4th edition of the Diagnostic and Statistical Manual of Mental Disorders (DSM-IV).

Group C (n 33, age range 96-100 years) included subjects who had a clinical diagnosis of dementia according to DSM-IV criteria (Mini Mental State Examination range 0-22). Twenty-eight had Alzheimer's disease (McKhann et al. 1984), four had vascular dementia (World Health Organization, 1992), and one suffered from Parkinson's disease. Fifteen patients of this group were institutionalized.

In order to exclude underlying medical conditions affecting amino acid metabolism, exclusion criteria for group $\mathrm{B}$ and $\mathrm{C}$ included clinical and/or laboratory evidence of cancer and cardiovascular, pulmonary, hepatic, renal, or endocrine-metabolic diseases.

The remaining eighty-six over-90-year-olds listed in our database were not included in the present study because no plasma specimens were available for amino acid profile determination and/or because of concomitant acute or chronic diseases. These subjects did not differ significantly from the study subjects as to age, gender, cognitive status, and anthropometric measurements, but were more often institutionalized ( $46 \%$ compared with $20 \%$ of the study subjects; $\left.\chi^{2}=11.006, P<0.001\right)$ and functionally 
dependent $(91 \%$ dependent in at least one of the six ADL compared with $70 \%$ of the study subjects; $\chi^{2}=9.595$, $P=0 \cdot 002$ ).

As a young control group, we used sixty healthy functionally independent individuals aged 25-50 years, recruited among the hospital staff from January 1995 to January 1996. They had no known acute or chronic illness, were not taking any medication, and did not follow special diet regimens. Their BMI was in the normal range for adults $\left(20-24.9 \mathrm{~kg} / \mathrm{m}^{2}\right)$ (Shenkin et al. 1996).

\section{Laboratory procedures}

A venous blood sample was taken from each participant between 6.00 and 9.00 hours, after an overnight fast. The blood samples of the oldest-old were collected at the subject's place of residence on the same morning as the medical examination, whereas the samples from the young controls were collected at our laboratory. In both cases, samples were put on ice and processed within $1 \mathrm{~h}$. Plasma samples were kept frozen at $-70^{\circ} \mathrm{C}$ until analysis.

Concentrations of plasma amino acids were determined with a 3A30 Carlo Erba Amino Analyser (Carlo ErbaFisons, Rodano, Milan, Italy) as described previously (Marchesini et al. 1987). In our laboratory, the intraassay and inter-assay $\mathrm{CV}$ in the determination of plasma amino acids were $\pm 5 \%$ and $\pm 10 \%$, respectively. According to storage studies at $-70^{\circ} \mathrm{C}$ (Hubbard \& Mejia, 1995), the amino acids measured in the present study are substantially stable in plasma except for the conversion of glutamine and asparagine into glutamic and aspartic acid respectively. For this reason, we calculated the sums of glutamine and glutamic acid and of asparagine and aspartic acid.

Additionally, serum creatinine, plasma total cholesterol, serum albumin, serum C-reactive protein, and serum insulin-like growth factor 1 (IGF-1) concentrations were assayed on frozen blood samples for all subjects as previously described (Ravaglia et al. 1996, 2000).

\section{Calculations}

Valine, leucine, and isoleucine were summed as branchedchain amino acids (BCAA). BCAA plus the aromatic amino acids Tyr and Phe were summed as large neutral amino acids (LNAA). BCAA along with Phe, methionine, threonine, lysine, and histidine were summed as EAA. Alanine, Gly, serine, glutamine, proline, Arg, taurine, glutamine + glutamic acid, asparagine + aspartic acid, ornithine, citrulline (Cit) and cystine were summed as non-essential amino acids (NEAA).

The following amino acid ratios were calculated: EAA: NEAA and Phe:Tyr, which are typically decreased in protein-energy malnutrition (Antener et al. 1981), and Cit:Arg and Gly:serine, which are typically increased in renal failure (Laidlaw et al. 1994). We also calculated Tyr: other LNAA and Phe:other LNAA because they are better predictors of Phe and Tyr availability to the brain than plasma concentrations (Lieberman, 1999).

Table 1. Clinical features of the study groups\|

(Mean values with their standard deviations)

\begin{tabular}{|c|c|c|c|c|c|c|c|c|c|}
\hline \multirow[t]{2}{*}{ Study group... } & \multicolumn{2}{|c|}{$\begin{array}{l}\text { Young controls } \\
(n 60)\end{array}$} & \multicolumn{2}{|c|}{$\begin{array}{l}\text { Group A } \\
(n 23)\end{array}$} & \multicolumn{2}{|c|}{$\begin{array}{l}\text { Group B } \\
(n 18)\end{array}$} & \multicolumn{2}{|c|}{$\begin{array}{l}\text { Group C } \\
(n 33)\end{array}$} & \multirow{2}{*}{$\begin{array}{c}P \text { value } \\
\text { (one-way ANOVA) }\end{array}$} \\
\hline & Mean & SD & Mean & SD & Mean & SD & Mean & SD & \\
\hline Age (years) & $28 \cdot 8$ & $7 \cdot 2$ & $96 \cdot 8^{*}$ & 4.9 & $96 \cdot 4^{*}$ & $4 \cdot 3$ & $101 \cdot 3 \dagger$ & $2 \cdot 2$ & $<0.001$ \\
\hline $\begin{array}{l}\text { Sex: male } \\
\text { female }\end{array}$ & \multicolumn{2}{|c|}{$\begin{array}{l}30 \\
30\end{array}$} & \multicolumn{2}{|c|}{$\begin{array}{l}10 \\
13\end{array}$} & \multicolumn{2}{|c|}{8} & \multicolumn{2}{|c|}{9} & $0 \cdot 208 \S$ \\
\hline \multicolumn{10}{|l|}{ Dependency in ADL } \\
\hline$\%$ & \multicolumn{2}{|c|}{100} & \multicolumn{2}{|c|}{40} & \multicolumn{2}{|c|}{22} & \multicolumn{2}{|c|}{6} & \\
\hline Dependent in 1-3 ADL: $n$ & \multicolumn{2}{|c|}{0} & \multicolumn{2}{|c|}{7} & \multicolumn{2}{|c|}{9} & \multicolumn{2}{|c|}{5} & \\
\hline & \multicolumn{2}{|c|}{0} & \multicolumn{2}{|c|}{30} & \multicolumn{2}{|c|}{50} & \multicolumn{2}{|c|}{15} & \\
\hline Dependent in > 3 ADL: $n$ & \multicolumn{2}{|c|}{0} & & & \multicolumn{2}{|c|}{5} & \multicolumn{2}{|c|}{26} & \\
\hline$\%$ & \multicolumn{2}{|c|}{0} & \multicolumn{2}{|c|}{30} & \multicolumn{2}{|c|}{28} & \multicolumn{2}{|c|}{79} & \\
\hline Serum albumin (g/l) & 41 & 2 & 40 & 5 & $37^{*}$ & 6 & $37^{*}$ & 3 & $<0.001$ \\
\hline Plasma cholesterol (mmol/l) & $4 \cdot 7$ & 1.5 & $5 \cdot 4$ & $1 \cdot 3$ & $5 \cdot 1$ & 0.9 & $4 \cdot 8$ & $1 \cdot 1$ & $0 \cdot 142$ \\
\hline Plasma triacylglycerols $(\mathrm{mmol} / \mathrm{l})$ & $1 \cdot 2$ & 0.4 & 1.4 & 0.7 & $1 \cdot 2$ & $0 \cdot 2$ & 1.4 & 0.3 & 0.073 \\
\hline Serum creatinine $(\mu \mathrm{mol} / \mathrm{l})$ & 78 & 20 & $117^{*}$ & 33 & $124^{\star}$ & 35 & $127^{*}$ & 28 & 0.001 \\
\hline BMI $\left(\mathrm{kg} / \mathrm{m}^{2}\right)$ & 23.9 & $2 \cdot 1$ & $24 \cdot 5$ & 3.9 & 23.5 & $2 \cdot 8$ & $21.5 \ddagger$ & 2.9 & $<0.001$ \\
\hline Arm muscle area $\left(\mathrm{cm}^{2}\right)$ & 38.00 & $9 \cdot 20$ & $33 \cdot 86^{*}$ & $8 \cdot 71$ & $29 \cdot 36^{*}$ & $5 \cdot 60$ & $24.47 \ddagger$ & $7 \cdot 32$ & $<0.001$ \\
\hline Arm fat area $\left(\mathrm{cm}^{2}\right)$ & $12 \cdot 58$ & $4 \cdot 21$ & $9 \cdot 94^{*}$ & $5 \cdot 77$ & $7 \cdot 61^{*}$ & 3.79 & $5.58 \ddagger$ & $2 \cdot 41$ & $<0.001$ \\
\hline
\end{tabular}

$A D L$, activities of daily living; IGF-1, insulin-like growth factor-1.

* $P<0.01$ compared with young controls (after adjustment for all pair-wise comparisons by Bonferroni's test).

$\dagger P<0.01$ compared with young controls, group $\mathrm{A}$, and $\mathrm{B}$ (after adjustment for all pair-wise comparisons by Bonferroni's test).

$\ddagger P<0.01$ compared with young controls and group A (after adjustment for all pair-wise comparisons by Bonferroni's test).

$\S \chi^{2}$ test.

\| For details of study groups and procedures, see p. 564. 


\section{Statistics}

Data are reported as mean and standard deviations or number and percentage except for plasma amino acid concentrations, which had markedly skewed distributions. In order to avoid the variety of mathematical transformations that would otherwise be required in order to fulfill the assumptions of normality for each amino acid, their plasma concentrations are reported as medians (25th-75th percentiles).

Differences in anthropometric, biochemical, and functional characteristics among the study groups were evaluated by one-way parametric ANOVA (Bonferroni's test for all pair-wise multiple comparisons) or $\chi^{2}$ test, as appropriate. Differences in plasma amino acid profile were evaluated by Kruskall-Wallis one-way ANOVA on ranks (Dunn's test for all pair-wise multiple comparisons). Gender-related differences among each study group were tested by Student's $t$ test or Mann-Whitney non-parametric test, as appropriate.

In order to investigate the relationship of plasma amino acid profile with the other study variables, Spearman rank correlation coefficients were calculated separately for the four study groups. Correlation coefficients were tested for significance at $P<0 \cdot 010$. This conservative a level was chosen to reduce the risk of type 1 errors based on the small number of study subjects and the large number of tests of significance being made.

Statistical calculations were performed by SYSTAT10 (SPSS Inc, Chicago, IL, USA).

\section{Results}

Table 1 displays the characteristics of the study groups. Independent of cognitive status, all oldest-old groups had lower serum IGF-1, higher serum creatinine, and lower arm muscle area and arm fat area values than young controls. Both group B and C had lower serum albumin than young controls whereas no difference was found for group A. Group C was older and had lower serum IGF-1, BMI, arm muscle area and arm fat area values than group A and B. Group C also had the highest percentage of dependent ADL. Because of the reduced number of oldest-old subjects and the lack of gender-related statistically significant differences in any of the variables of interest except for arm muscle area values of young controls (men 41.53 (SD 9.10) $\mathrm{cm}^{2}$, women 33.61 (SD 6.42) $\mathrm{cm}^{2}$; $P<0.001)$, men and women of each study group were pooled.

Tables 2 and 3 report the amino acid profile of young controls and oldest-old groups. No gender-related difference was found for any of the measured plasma amino acids. Independent of cognitive status, all the three oldest-old groups had higher Cit, cystine, asparagine + aspartate, glutamine + glutamic acid, and 3-methylhistidine plasma values, and lower EAA:NEAA and higher Tyr:other LNAA and Cit:Arg than young controls. Group A was further characterized by lower BCAA than young controls. Group B and group C had higher Gly plasma values and higher Phe:other LNAA and Gly:serine than young controls. 
Table 3. Fasting plasma non-essential amino acid profile of the young controls and oldest-old groups $\dagger$ (Median values and 25th-75th percentiles)

\begin{tabular}{|c|c|c|c|c|c|c|c|c|c|}
\hline \multirow{2}{*}{$\begin{array}{l}\text { Study group ... } \\
\text { Amino acid ( } \mu \mathrm{mol} / \mathrm{l})\end{array}$} & \multicolumn{2}{|c|}{ Young controls ( $n 60)$} & \multicolumn{2}{|c|}{ Group A (n 23) } & \multicolumn{2}{|c|}{ Group B ( $n 18)$} & \multicolumn{2}{|c|}{ Group C ( $n 35)$} & \multirow[b]{2}{*}{$P$ value } \\
\hline & Median & 25th-75th percentiles & Median & 25th-75th percentiles & Median & 25th-75th percentiles & Median & 25th-75th percentiles & \\
\hline Alanine & 352 & $289-429$ & 337 & $272-450$ & 391 & $297-480$ & 330 & $330-463$ & 0.355 \\
\hline Glycine & 213 & $189-255$ & 219 & $196-283$ & 275 & $224-378^{\star}$ & 263 & $210-316^{*}$ & 0.004 \\
\hline Serine & 104 & $85-124$ & 96 & $81-111$ & 97 & $87-129$ & 103 & $85-124$ & 0.254 \\
\hline Proline & 257 & $202-366$ & 233 & $148-262$ & 225 & $166-304$ & 228 & $183-307$ & 0.080 \\
\hline Taurine & 68 & $34-125$ & 51 & $41-64$ & 56 & $40-74$ & 58 & $45-69$ & 0.485 \\
\hline Tyrosine & 60 & $48-77$ & 58 & $49-63$ & 69 & $53-104$ & 69 & $56-88$ & 0.055 \\
\hline Ornithine & 102 & $72-127$ & 89 & $70-110$ & 92 & $68-109$ & 90 & $73-124$ & 0.623 \\
\hline Citrulline & 27 & $0-60$ & 56 & $50-72^{*}$ & 60 & $42-72^{*}$ & 72 & $53-85^{\star}$ & $<0.001$ \\
\hline Arginine & 66 & $39-82$ & 66 & $58-86$ & 73 & $62-99$ & 76 & $62-98$ & 0.051 \\
\hline Cystine & 13 & $5-23$ & 52 & $33-68^{*}$ & 46 & $33-69^{*}$ & 64 & $39-84^{*}$ & $<0.001$ \\
\hline Asparagine+aspartate & 102 & $76-133$ & 144 & $118-170^{\star}$ & 153 & $110-197^{*}$ & 123 & $156-185^{\star}$ & $<0.001$ \\
\hline Glutamine+glutamate & 491 & $435-565$ & 632 & $523-714^{*}$ & 638 & $455-795^{\star}$ & 684 & $536-802^{*}$ & $<0.001$ \\
\hline 3-Methylhistidine & 2 & $2-2$ & 6 & $4-7^{\star}$ & 5 & $0-7^{\star}$ & 6 & $4-9^{*}$ & 0.001 \\
\hline EAA:NEAA & 0.47 & $0.44-0.53$ & 0.39 & $0.33-0.45^{\star}$ & 0.41 & $0.35-0.46^{*}$ & 0.39 & $0.35-0.43^{*}$ & $<0.001$ \\
\hline Phenylalanine:tyrosine & 0.9 & $0.8-1.1$ & 0.9 & $0.7-1.0$ & 0.9 & $0.7-1.0$ & 0.9 & $0.7-1.0$ & 0.923 \\
\hline Citrulline:arginine & 0.3 & $0.1-0.8$ & 0.9 & $0.6-1.0^{*}$ & 0.8 & $0.6-0.8^{\star}$ & 0.8 & $0.7-1.0^{*}$ & $<0.001$ \\
\hline Glycine:serine & $2 \cdot 1$ & $1.8-2.5$ & $2 \cdot 3$ & $2 \cdot 0-2 \cdot 6$ & 2.6 & $2 \cdot 2-3 \cdot 4^{\star}$ & 2.4 & $2 \cdot 1-2 \cdot 7^{*}$ & 0.003 \\
\hline
\end{tabular}

EAA, essential amino acids; NEAA, non-essential amino acids.

Wlis ANOVA after adjustment for all pair-wise comparisons by Dunn's test).

tFor details of study groups and procedures, see p. 564 . 
A general linear multivariate model taking into account age, gender and institutionalization as possible confounding factors was performed (after appropriate normalization) for all the variables that were statistically different across groups at one-way ANOVA. All results were confirmed except for Gly values and Gly:serine of group $\mathrm{B}$ and $\mathrm{C}$ which were no longer statistically different from those of young controls.

No significant correlation between amino acid profile and any of the study variables was found in young controls. The most consistent association across the three oldest-old groups was between arm muscle area and EAA:NEAA
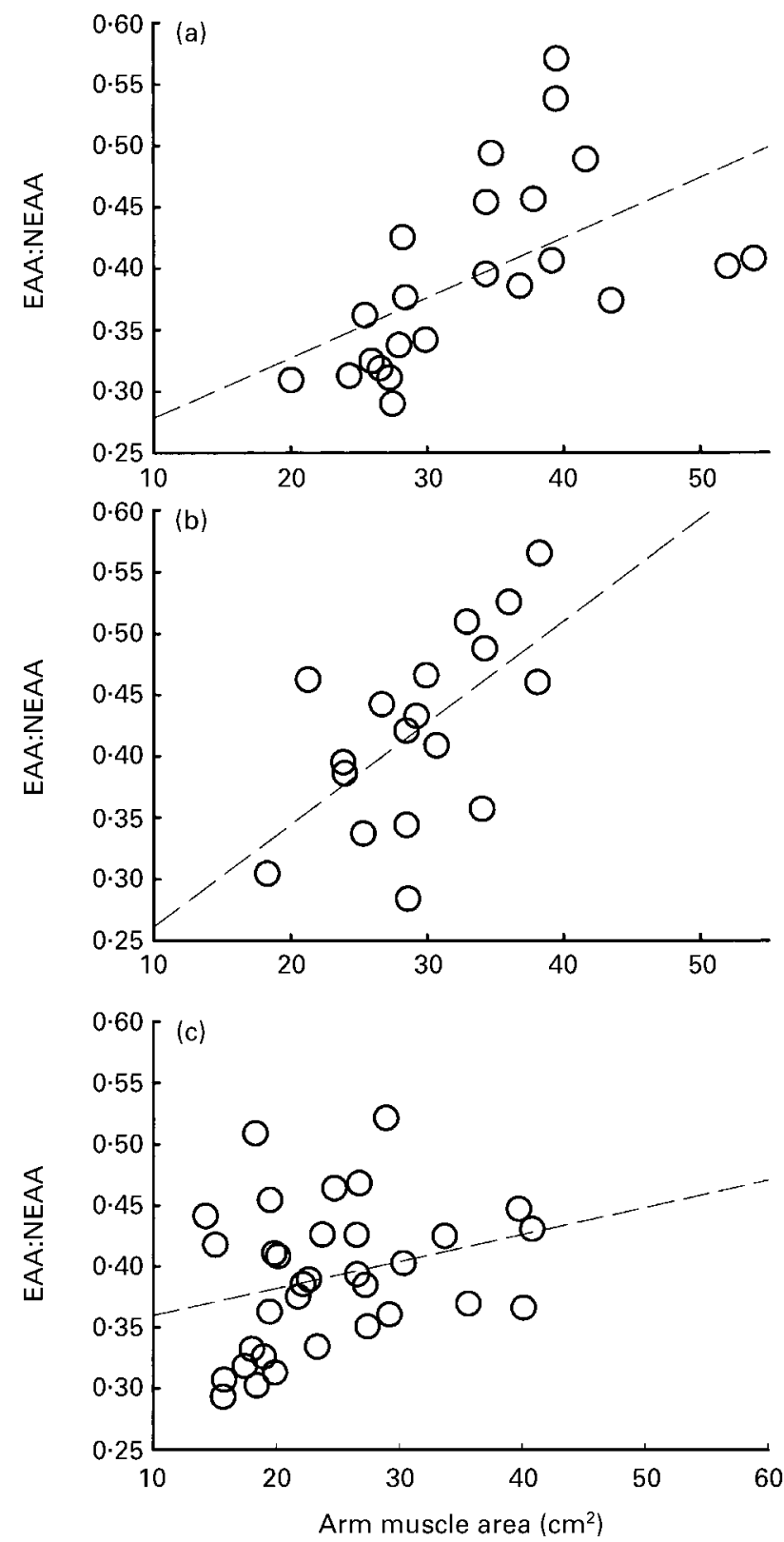

Fig. 1. Relationships between arm muscle area and essential:nonessential amino acids (EAA:NEAA) in subjects aged $\geq 90$ years with (a) normal cognition (group $A ; r 0.739, P<0.001$ ); (b) mild cognitive impairment without dementia (group B; $r$ 0.602, $P=0.008$ ); (c) dementia (group C: $r 0.441, P=0.009$ ).
(Fig. 1). In group A, arm muscle area was also positively associated with valine $(r 0.556, P=0.006)$. In group $C$, arm fat area was positively associated with Phe, leucine, and histidine (Fig. 2), whereas the number of dependent ADL was negatively associated with EAA:NEAA (Fig. 3). A non-significant trend towards positive associations was found for both serum albumin and BMI with EAA:NAA across all the oldest-old groups ( $P$ values between $0 \cdot 10$ and 0.05$)$, and a marginally significant positive association $(r-0.363, P=0.032)$ was found for BMI and Phe in group C. Serum creatinine was positively associated with cystine
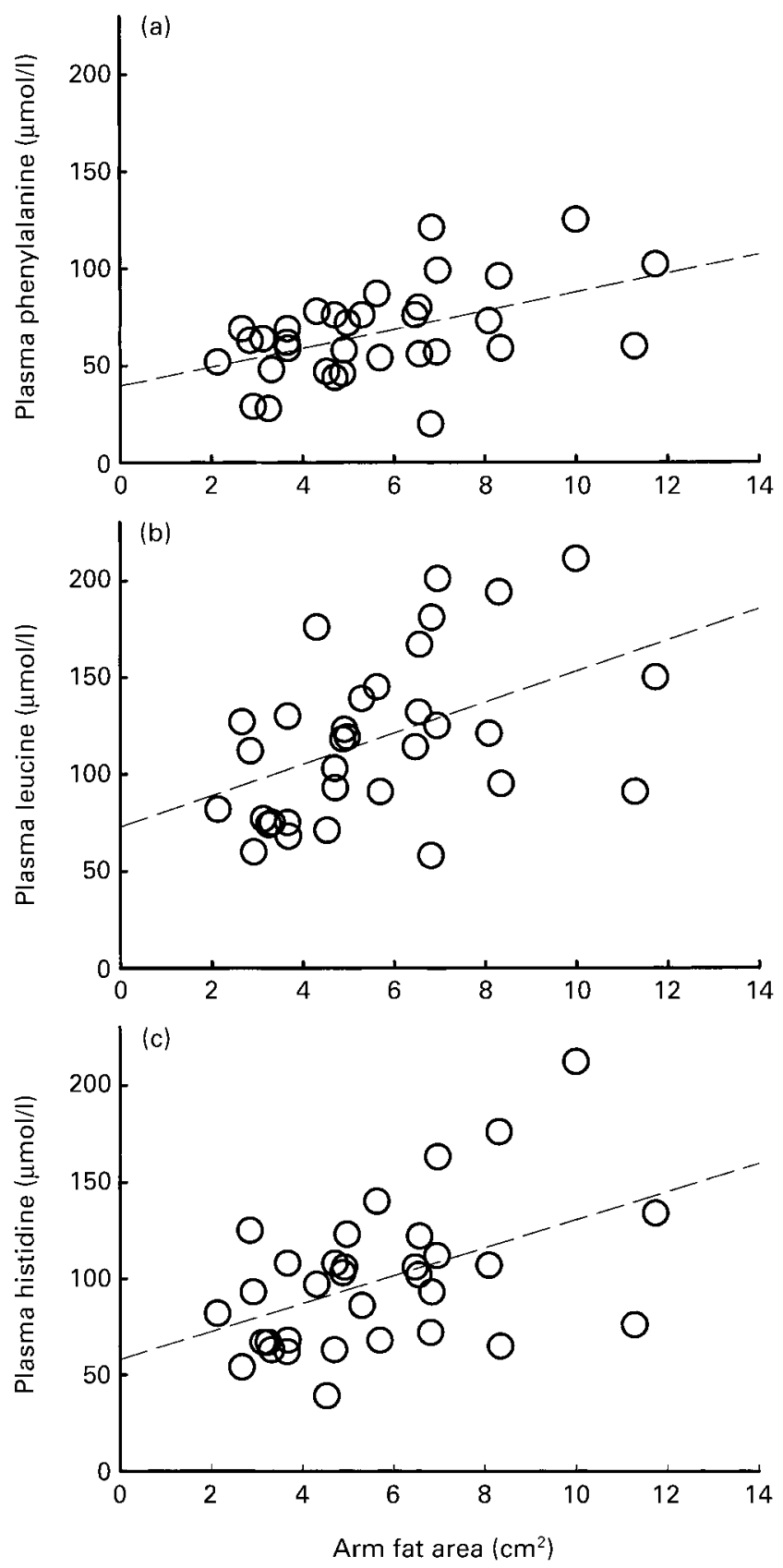

Fig. 2. Relationships between arm fat area and plasma concentrations of (a) phenylalanine $(r 0.490, P=0.004)$, (b) leucine $(r 0.498$, $P=0.003)$ and (c) histidine $(r 0.472, P=0.005)$ in subjects with dementia aged $\geq 90$ years. 


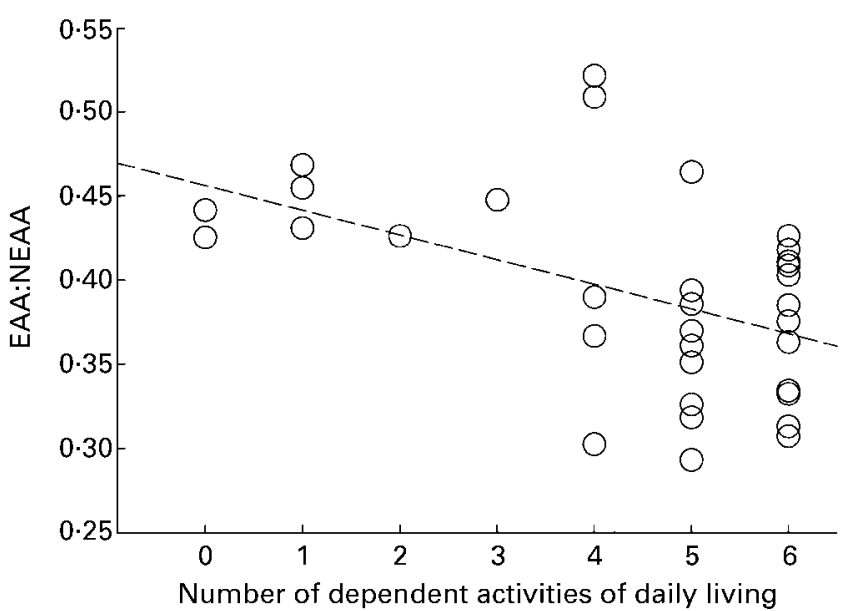

Fig. 3. Relationship between the number of dependent activities of daily living and essential:non-essential amino acids (EAA:NEAA) in subjects with dementia aged $\geq 90$ years $(r-0.470, P=0.006)$.

( $r 0.651, P=0.001)$ and leucine $(r 0.556, P=0.007)$ in group A, and with 3-methylhistidine $(r 0.638, P=0.006)$ in group B. No other statistically significant correlation was found between plasma amino acid profile and the variables of interest. It must be remembered, however, that due to the rather conservative choice for $\alpha$ level, the probability of type 2 errors is large.

\section{Discussion}

The present study showed that the fasting plasma amino acid profile of oldest-old individuals with varying degree of cognitive impairment is different from that of the young adults, is associated with some anthropometric parameters of body composition and, in oldest-old patients with dementia, with functional dependency.

Our study has two major strengths. First, very few studies have focused on fasting plasma amino acid profiles of elderly people. Second, we adopted very strict selection criteria in order to avoid the confounding effect of any pathological conditions other than cognitive problems on nutritional status and amino acid metabolism.

The present study also has several important limitations. First, plasma amino acids represent only a small fraction of the total body content, are subjects to many sources of variation other than diet, and are in constant state of exchange with intracellular protein pools (Young, 1990). Therefore, as also suggested by the lack of statistically significant associations in functionally independent healthy young controls, interpretation of any relationship between plasma values of single amino acids and other variables in older people requires extreme caution. Second, we did not measure the essential amino acid tryptophan, although tryptophan is an LNAA precursor of the neurotransmitter serotonin. The brain tryptophan supply, however, is a function of the relative concentrations of free and albuminbound pool of tryptophan in blood (Pardridge \& Fierer, 1990). Because the method we employed in order to assess plasma amino acid profile did not allow a reliable measurement of free tryptophan, we did not include tryptophan among the study variables. Third, we pooled men and women because of the reduced number of study subjects. Although from a biological point of view gender is very likely to represent a confounding factor for several of our study variable, no gender-related differences were found in univariate analysis except for muscle mass in young controls, and a multivariate analysis taking gender into account was unable to add significant information to our results, perhaps as a consequence of the small group sizes. Noteworthy, gender-related differences have been reported for some amino acids in young subjects but not in aged subjects (Caballero et al. 1991). Finally, for practical reasons related to the extreme age of our study subjects, we could not measure dietary intake of energy and protein. This information would have been very useful to assess the adequacy of recent nutritional intake and to understand better the cause of protein-energy malnutrition in individuals exhibiting anthropometric and/or biochemical signs of this condition. Values of BMI $\left(<20 \mathrm{~kg} / \mathrm{m}^{2}\right)$ and/or serum albumin $(<35 \mathrm{~g} / \mathrm{l})$ consistent with a diagnosis of mild protein-energy malnutrition (Shenkin et al. 1996) were found in none of the SENIEUR oldest-old, $39 \%$ of the oldest-old subjects who were cognitively impaired without dementia and $42 \%$ of all patients with dementia. As expected from previous studies, an age-related reduction in muscle (sarcopenia) (Melton et al. 2000), fat mass (Ravaglia et al. 1997b), and circulating levels of the anabolic hormone IGF-1 (Flier \& Underhill, 1997) were also observed in all oldest-old individuals, independent of cognitive function. With respect to the SENIEUR group, however, patients with dementia not only had a reduced muscle mass (which could be due to both an inadequate protein-energy intake and inactivity-induced atrophy), but also a reduced fat mass, which is an index of body energy stores (Frisancho, 1981), and reduced values of serum IGF-1, which has been suggested to be a far more sensitive marker of undernutrition than circulating visceral proteins (Shenkin et al. 1996).

A first finding of the present study is that, independent of cognitive function, EAA:NEAA of all oldest-old groups was reduced with respect to young controls and positively associated with muscle mass. A reduction in EAA:NEAA has been already reported in elderly (Rudman et al. 1989; Jeevanandam et al. 1990) and oldest-old subjects (Bancel et al. 1994), and might be suggestive of a diet only marginally deficient in energy but containing an insufficient amount of proteins (Shenkin et al. 1996). The replacement of dietary proteins with carbohydrates, which are less expensive, more palatable, and more easily chewable, is a common nutritional mistake even among healthy elderly people because of dentition and socio-economic problems (Thomas, 1998). Our finding of low EAA:NEAA values and BCAA concentrations even in the highly selected SENIEUR subjects is in agreement with the view that dietary deficits may be very frequent even among apparently healthy elderly subjects (Ravaglia et al. 2000).

In the oldest-old with overt dementia, plasma availability of some EAA (Phe, leucine, histidine) was also associated with fat mass. Preservation of fat mass requires an adequate energy intake and, on their part, EAA cannot be synthesized by the body but must be obtained from 
the diet. This, along with the great variability observed for these EAA plasma values in patients with dementia, suggests that these subjects might have a diet not only inadequate in its protein-energy content but also very unbalanced in its amino acid composition.

The fact that none of our study subjects exhibited clinical or biochemical signs of inflammation (serum C-reactive protein $>8 \mathrm{mg} / \mathrm{l}$ ) may explain why we did not find the general decrease of both EAA and NEAA reported by Polge et al. (1997) in hospitalized oldest-old patients with severe malnutrition (average BMI $<17 \mathrm{~kg} / \mathrm{m}^{2}$, average serum albumin $<30 \mathrm{~g} / \mathrm{l})$ and a large prevalence of hypermetabolic states (average serum $\mathrm{C}$ protein $>5 \mathrm{mg} / \mathrm{l}$ ).

BMI (Group A: $r=0.364, \quad P=0.087$; Group B: $r=0.355, P=0.146$; Group C: $r=0.070, P=0.686)$ and serum albumin (Group A: $r=0.223, P=0.301$; Group B: $r=0.225, P=0.360$; Group $\mathrm{C}: r=0.060, P=0.732) \mathrm{did}$ not associate significantly with amino acid profile as we observed for arm fat area and arm muscle area. This agrees with previous suggestions that serum albumin by itself is unreliable as a nutritional marker because of the wide range of physiopathological conditions affecting its blood levels (Shenkin et al. 1996), and that upper arm anthropometry may provide better nutritional parameters than BMI in older subjects because of the high frequency of motor and spinal impairments affecting stature and weight measurement (World Health Organization, 1998).

Among oldest-old patients with dementia, we also found a striking positive association between EAA:NEAA and functional impairment. In particular, about $88 \%$ of the patients who had EAA:NEAA values below the 25 th percentile for young controls $(0.44)$ were dependent in three or more dependent ADL. This relationship may be easily explained by the fact that cognitive impairment affects the ability to independently select and eat food.

Kidneys play an important role in NEAA metabolism, and increases in cystine, aspartic and glutamic acid plasma concentrations and in Cit:Arg as those observed in our oldest-old subjects have been reported in renal failure (Fiorini \& Cavatorta, 1997). Similarly, a loss of renal excretory capacity elevates the plasma concentrations of 3-methylhistidine, which is excreted by the kidney as a waste product of protein metabolism and whose plasma concentrations are highly reflective of renal function even at early stages of renal impairment (Laidlaw et al. 1994). Both ageing (Niederstadt \& Steinhoff, 1997) and malnutrition (Benabe \& Martinez-Maldonado, 1998) may be associated with a progressive deterioration of renal function, but alterations of the fasting amino acid profile clearly consistent with a reduced renal function have not been previously reported in the elderly (Rudman et al. 1989; Jeevanandam et al. 1990; Bancel et al. 1994; Polge et al. 1997). Only a few significant associations were found in the present study between plasma amino acids and serum creatinine of the oldest-old, but this could be a consequence of the small number of subjects in each group, of the very conservative $\alpha$ level chosen, and of the fact that, in the elderly, changes in serum creatinine levels due to a reduced renal function may be masked by the concurrent reduction in muscle mass (Fastbom et al. 1996).

Finally, the amino acid profile of the oldest-old subjects was characterized by a relative increase in plasma aromatic amino acids with respect to other LNAA. According to Rudman et al. (1991), elderly people may suffer from a limitation in the capacity of the homogentisic acid pathway, the common hepatic degradative pathway of Phe and Tyr, which could potentially reduce the dietary requirements and the tolerance to aromatic amino acids in elderly people. This limitation might be relevant to cognitive function because aromatic amino acids act as catecholaminergic precursors. Since all LNAA are actively transported across the blood-brain barrier by the same carrier mechanism, aromatic amino acids compete with other LNAA for transport into the brain (Lieberman, 1999). Therefore, an increased influx of Phe or Tyr may alter the balance between catecholaminergic and serotoninergic function due to the competition of aromatic amino acids with the serotoninergic precursor tryptophan (Hargreaves \& Pardridge, 1988). Moreover, Phe and its metabolites may have toxic effects on the brain (Huttenlocher, 2000).

In normal adult human subjects, convincing experimental evidence of an association between cognitive performance and fasting plasma concentrations of specific LNAA has been reported for tryptophan only (Lieberman, 1999). Data about the possible association between dementia and plasma LNAA in the elderly are also scant and contrasting (Bonaccorso et al. 1998; Fekkes et al. 1998), but increases in Phe:LNAA have been recently reported in association with delirium (Flacker \& Lipsitz, 2000).

In conclusion, we found several differences in plasma amino acid profile between young controls and oldest-old subjects with different degrees of cognitive impairment. Because some of these changes, in particular the abnormalities of aromatic amino acids availability, could contribute to the cause of or aggravate concurrent neurological and behavioural problems of oldest-old individuals with cognitive disorders, further research is needed about amino acid requirements in the extreme decades of human life.

\section{Acknowledgements}

This study was supported by grants from Ministero dell'Università e della Ricerca Scientifica (ex-60\% fund).

\section{References}

American Psychiatric Association (1994) Diagnostic and Statistical Manual of Mental Disorders, 4th ed: DSM-IV. Washington, DC: American Psychiatric Association.

Antener I, Tonney G, Verwilghen AM \& Mauron J (1981) Biochemical study of malnutrition. Part IV. Determination of amino acids in the serum, erythrocytes, urine and stool ultrafiltrates. International Journal for Vitamin and Nutrition Research 51, 64-78.

Bancel E, Strubel D, Bellet H, Polge A, Peray P \& Magnan de Bornier B (1994) Effet de l'age et du sexe sur les concentrations des acides amines plasmatiques (Effect of the age and the sex on plasma concentration of amino acids). Annales de Biologie Clinique 52, 667-670.

Benabe JE \& Martinez-Maldonado M (1998) The impact of 
malnutrition on kidney function. Mineral and Electrolyte Metabolism 24, 20-26.

Bonaccorso S, Lin A, Song C, Verkerk R, Kenis G, Bosmans E, Scharpe S, Vandewoude M, Dossche A \& Maes M (1998) Serotonin-immune interactions in elderly volunteers and in patients with Alzheimer's disease (DAT): lower plasma tryptophan availability to the brain in the elderly and increased serum interleukin-6 in DAT. Aging Clinical and Experimental Research 10, 316-323.

Caballero B, Gleason RE \& Wurtman RJ (1991) Plasma amino acid concentrations in healthy elderly men and women. American Journal of Clinical Nutrition 53, 1249-1252.

Chumlea WC, Roche AF \& Steinbaugh ML (1985) Estimating stature from knee height for persons 60 to 90 years of age. Journal of the American Geriatric Society 33, 116-121.

Constans T, Alix E \& Dardaine V (2000) Malnutrition protéinoénergetique: Méthodes diagnostiques et épidémiologie (Protein-energy malnutrition. Diagnostic methods and epidemiology). Presse Medicale 29, 2171-2176.

Cummings JL (1993) Mini-Mental State Examination: norms, normals and numbers. JAMA 269, 2420-2421.

Fastbom J, Wills P, Cornelius C, Viitanen M \& Winblad B (1996) Levels of serum creatinine and estimated creatinine clearance over the age of 75: a study of an elderly Swedish population. Archives of Gerontology and Geriatrics 23, 179-188.

Fekkes D, van der Cammen TJ, van Loon CP, Verschoor C, van Harskamp F, de Konig I, Schudel WJ \& Pepplinkhuinzen L (1998) Abnormal amino acid metabolism in patients with early stage Alzheimer dementia. Journal of Neural Transmission 105, 287-294.

Felig P \& Bergman M (1995) The endocrine pancreas: diabetes mellitus. In Endocrinology and Metabolism, 3rd ed. pp. 1107-1250 [P Felig, J Baxter and LA Frohman, editors]. New York: McGraw Hill.

Fiorini F \& Cavatorta F (1997) Protein and amino acid metabolism in chronic renal failure. Minerva Urologica e Nefrologica 49, 189-197.

Flacker JM \& Lipsitz LA (2000) Large neutral amino acid changes and delirium in febrile elderly medical patients. Journal of Gerontology Biological Sciences 55A, B249-B252.

Flier JS \& Underhill LH (1997) Insulin-like growth factors. New England Journal of Medicine 336, 633-640.

Frisancho AR (1981) New norms of upper limb fat and muscle area for assessment of nutritional status. American Journal of Clinical Nutrition 34, 2540-2545.

Hargreaves KM \& Pardridge WM (1988) Neutral amino acid transport at the human blood brain barriers. Journal of Biological Chemistry 263, 19392-19397.

Hubbard RW \& Mejia A (1995) Human plasma preservation for amino acid analysis by immediate low temperature freezing. Clinical Biochemistry 28, 318-320.

Huttenlocher PR (2000) The neuropathology of phenylketonuria: human and animal studies. European Journal of Pediatrics 159, S102-S106.

Jeevanandam M, Young DH, Ramias L \& Schiller WR (1990) Effect of major trauma on plasma free amino acid concentrations in geriatric patients. American Journal of Clinical Nutrition 51, 1040-1045.

Katz S, Downs TD, Cash HR \& Grotsz RC (1970) Progress in development of the index of ADL. Gerontologist 10, 20-30.

Laidlaw SA, Berg RL, Kopple JD, Naito H, Walker WG \& Walser M (1994) Patterns of fasting plasma amino acid levels in chronic renal insufficiency: results from the feasibility phase of the modification of diet in Renal Disease Study. American Journal of Kidney Diseases 23, 504-513.

Lieberman HR (1999) Amino acid and protein requirements: cognitive performance, stress, and brain function. In The Role of Protein and Amino Acids in Sustaining and Enhancing Performance, pp. 289-307 (Committee on Military Nutrition Research - Committee on Body Composition, Nutrition and Health). Washington, DC: National Academy Press.

Ligthart GJ, Corberand JX, Fournier C, Galanaud P, Hijmans W, Kennes B, Muller-Hermelink HK \& Steinmann GG (1984) Admission criteria for immunogerontological studies in man: the SENIEUR protocol. Mechanisms of Ageing and Development 28, 47-55.

McKhann G, Drachman D, Folstein M, Katzman R, Price D \& StADLan EM (1984) Clinical diagnosis of Alzheimer's disease: report of NINCDS-ADRDA Work group under the auspices of Department of Health and Human Services Task Force on Alzheimer's disease. Neurology 34, 939-944.

Marchesini G, Bianchi GP, Vilstrup H, Checchia GA, Patrono D \& Zoli M (1987) Plasma clearances of branched-chain amino acids in control subjects and in patients with cirrhosis. Journal of Hepatology 4, 108-117.

Melton LJ III, Khosla S \& Riggs BL (2000) Epidemiology of Sarcopenia. Mayo Clinic Proceedings 75, Suppl., S10-S13.

Niederstadt C \& Steinhoff J (1997) Die Nieren im Alter (The kidneys in ageing). Zeitschrift für Gerontologie und Geriatrie 30, 200-207.

Pardridge WM \& Fierer G (1990) Transport of tryptophan into brain from circulating, albumin-bound pools in rats and rabbits. Journal of Neurochemistry 54, 971-976.

Polge A, Bancel E, Bellet H, Strubel D, Poirey S, Peray P, Carlet C \& Magnan de Bornier B (1997) Plasma amino acid concentrations in elderly patients with protein energy malnutrition. Age and Ageing 26, 457-462.

Ravaglia G, Forti P, De Ronchi D, Maioli F, Nesi B, Cucinotta D, Bernardi M \& Cavalli G (1999) Prevalence and severity of dementia among northern Italian centenarians. Neurology 53, 416-418.

Ravaglia G, Forti P, Maioli F, Boschi F, Bernardi M, Pratelli L, Pizzoferrato A \& Gasbarrini G (1996) The relationship of dehydroepiandrosterone sulfate (DHEAS) to endocrinemetabolic parameters and functional status in the oldestold. Results from an Italian study on healthy free-living over-ninety-year-olds. Journal of Clinical Endocrinology and Metabolism 81, 1173-1178.

Ravaglia G, Forti P, Maioli F, Boschi F, Cicognani A, Beranrdi M, Pratelli L, Pizzoferrato A, Porcu S \& Gasbarrini G (1997a) Determinants of functional status in healthy Italian nonagenarians: a comprehensive functional assessment by the instruments of geriatric practice. Journal of the American Geriatric Society 45, 1196-1202.

Ravaglia G, Forti P, Maioli F, Nesi B, Pratelli L, Savarino L, Cucinotta D \& Cavalli G (2000) Blood micronutrient and thyroid hormone concentrations in the oldest-old. Journal of Clinical and Endocrinology Metabolism 85, 2260-2265.

Ravaglia G, Morini P, Forti P, Maioli F, Bernardi M \& Gasbarrini G (1997b) Anthropometric characteristics of healthy Italian nonagenarians and centenarians. British Journal of Nutrition 77, 9-17.

Raynaud-Simon A \& Lesourd B (2000) Dénutrition du sujet agé: Conséquences cliniques (Malnutrition in the elderly. Clinical consequences). Presse Medicale 29, 2183-2190.

Ritchie K \& Kildea D (1995) Is senile dementia "age-related" or "ageing-related"? Evidence from meta-analysis of dementia prevalence in the oldest-old. Lancet 346, 931-934.

Rudman D, Abbasi AA, Chaudry F \& Mattson DE (1991) Delayed plasma clearance of phenylalanine and tyrosine in elderly men. Journal of the American Geriatric Society 39, 33-38.

Rudman D, Mattson D, Feller AG, Cotter R \& Johnson RC (1989) Fasting plasma amino acids in elderly men. American Journal of Clinical Nutrition 49, 559-566. 
Schlienger JL, Pradignac A \& Grunenberger F (1995) Nutrition of the elderly: a challenge between facts and needs. Hormone Research 43, 46-51.

Shenkin A, Cederblad G, Elia M \& Isaksson B (1996) Laboratory assessment of protein-energy status. Clinica Chimica Acta 253, S5-S59.

Thomas AJ (1998) Nutrition. In Brocklehurst's Textbook of Geriatric Medicine and Gerontology, 5th ed., pp. 899-912 [R Tallis, H Fillit and JC Brocklehurst, editors]. Edinburgh: Churchill Livingstone.

Valente C, Maione P, Lippi A, Taiti P, Cavarzeran F, Rocca WA, Amaducci L \& Bavazzano A (1992) Validazione del Mini Mental State Examination (MMSE) come strumento di screening per demenza in una popolazione Italiana (Validation of the Mini Mental State Examination (MMSE) as a screening instrument for dementia in an Italian Population). Giornale di Gerontologia 40, 161-165.

World Health Organization (1992) The International Classification of Diseases, 10th revision: ICD-10. Geneva: WHO.

World Health Organization (1998) Expert Subcommittee on the Use and Interpretation of Anthropometry in the Elderly: Uses and interpretation of anthropometry in the ederly for the assessment of physical status Report to the Nutrition Unit of the World Health Organization. Journal of Nutrition, Health and Aging 2, 5-17.

Young V (1990) Amino acids and proteins in relation to the nutrition of elderly people. Age and Ageing 19, S10-S24.

Zoli M, Marchesini G, Angiolini A, Dondi C, Bianchi FB \& Pisi E (1981) Plasma amino acids as markers of liver dysfunction in cirrhotics. Scandinavian Journal of Gastroenterology 16, 689-692. 